The IJA is a peer-reviewed open-access, electronic journal, freely available without charge to users

\title{
Grape seed proanthocyanidins alleviate the negative effects of dietary cadmium on pearl gentian grouper (Epinephelus fuscoguttatus female x Epinephelus lanceolatus male)
}

\author{
Ziyue Jia\#, Yuting Tan\#, Yuming Liu\#, Guohe Cai, Xuehao Chen, \\ Shaowei Zhai* \\ Xiamen Key Laboratory of Feed quality testing and Safety Evaluation, \\ Fisheries College of Jimei University, Xiamen, 361021, China
}

Key words: Cadmium, Grape seed proanthocyanidins, Pearl Gentian Grouper, Growth performance, Intestinal health

\begin{abstract}
The present study was conducted to evaluate whether grape seed proanthocyanidins (GSPs) could alleviate the negative effects of dietary cadmium on growth performance, body composition, activities of digestive enzymes, and antioxidant potential in the intestine of pearl gentian grouper (Epinephelus fuscoguttatus female $\times$ Epinephelus lanceolatus male). Two hundred and forty pearl gentian groupers with the initial average body weight of $31.30 \pm 0.05 \mathrm{~g} /$ fish were randomly divided into four treatment groups with three replicates in each group and 20 fish in each replicate. The four treatment groups were identified as control group (the basal diet), Cd group (the basal diet+300 mg/kg Cd), Cd+GSPs group I (the basal diet $+300 \mathrm{mg} / \mathrm{kg} \mathrm{Cd}+400 \mathrm{mg} / \mathrm{kg}$ GSPs), and Cd+GSPs group II (the basal diet+300 mg/kg Cd+800 mg/kg GSPs group), respectively. The trial lasted for 42 days. Fish exposed to $300 \mathrm{mg} / \mathrm{kg}$ dietary cadmium had lower growth performance, mineral metabolism disorders with lower calcium and phosphorus levels, higher ash level, decreased lipase and protease activities, and antioxidant potential in the intestine. Dietary GSPs supplementation could counteract those negative effects to a certain extent. The alleviation effects of Cd+GSPs group II were better than those of Cd+GSPs group I. Except for calcium and phosphorus levels in whole fish composition, $800 \mathrm{mg} / \mathrm{kg}$ dietary GSPs supplementation could not recover the adverse effects caused by Cd stress. These results suggested that GSPs might potentially mediate dietary cadmium toxicity and alleviate the negative effects on pearl gentian grouper.
\end{abstract}

\footnotetext{
* Corresponding author: Tel: +86 592 6181420, Fax: +86 592 6181476. e-mail: zhaisw@jmu.edu.cn

\# These authors contributed equally to this work.
} 


\section{Introduction}

Cadmium (Cd) is a highly toxic element and is naturally spread in feed of aquatic animals. As one of the ubiquitously distributed toxins in the aquatic system, it can disrupt growth, reproduction, the immune system, endocrine, development, and behavior (Mai et al., 2006; Cui et al., 2016; Zhai et al., 2018). The toxic effect of $\mathrm{Cd}$ is mediated through oxidative damage to cellular organelles by inducing the generation of reactive oxygen species (ROS), such as superoxide ion, hydroxyl radicals, and hydrogen peroxide, which may damage protein, lipid, enzymes, and DNA. Antioxidants must neutralize these ROS before entering cells (Alkhedaide et al., 2016; El-Tarras et al., 2016; Zhai et al., 2018).

In recent years, grape seed proanthocyanidins (GSPs) have attracted extensive attention as potential scavengers for ROS to alleviate oxidative stress. They are oligomeric compounds formed from catechin and epicatechin molecules, and have many other activities including antibacterial, antiviral, anticarcinogenic, anti-inflammatory, anti-allergic, and vasodilatory actions (Fine, 2000). In previous studies, GSPs were reported to attenuate the oxidative damage in tissue and organs, such as blood (Evcimen et al., 2020), liver (Miltonprabu et al., 2016), kidney (Nazima et al., 2015), testes (Morsi et al., 2020), brain (El-Tarras et al., 2016), pancreas (Nazima et al., 2016), and prostate (Lei et al., 2017) of rats exposed to dietary Cd. These ameliorative effects of GSPs on cadmium-induced oxidative stress were also shown in mice kidney (Chen et al., 2013) and chicken embryos (Hou et al., 2016). Similar protective effects of dietary GSPs on aquatic animals were found in tilapia (Oreochromis niloticus) with dietary Cd exposure (Zhai et al., 2018), American eel (Anguilla rostrata) exposed to high dietary histamine (Zhai et al., 2020), and greenlip abalone (Haliotis laevigata Donovan) under heat stress (Shiel et al., 2017).

At present, no studies regarding GSPs efficacy in attenuating Cd-induced oxidative stress have been conducted in seawater fish. The pearl gentian grouper (Epinephelus fuscoguttatus female $x$ Epinephelus lanceolatus male), a marine carnivorous fish species, has the advantages of fast growth, high market value, and strong disease resistance. It is a new candidate which is widely cultured in China and over the world (Liu et al., 2018). This study aimed to evaluate the effects of GSPs on alleviating dietary Cd-induced growth retardation and damages of intestinal health parameters in pearl gentian grouper.

\section{Materials and Methods}

\section{Experimental fish and cultivation}

Healthy Pearl gentian grouper, purchased from Xiamen (China) Xiaodeng Fisheries Science and Technology Co., LTD, were acclimatized in a circular aquaria of 1000 L. Aerated water was provided to the circular culture system with additional aeration provided by an air pump. After adapting to experimental conditions, the fish were kept in the circular aquaria of $150 \mathrm{~L}$ (water capacity of 120 L) (Qingdao Zhongke Seawater Treatment Co., Ltd.). Fish were fed to satiation two times daily (at 8:00 h, and 18:00 h). Thirty minutes after feeding, uneaten pellets and feces were siphoned out. Water quality was monitored twice weekly with a multiparameter photome (HI9804N, HANNA, Baranzate, MI, Italy). Values of dissolved oxygen, $\mathrm{pH}$, salinity and ammonia- $\mathrm{N}$ ranged between $7.0-9.2 \mathrm{mg} / \mathrm{L}, 7.1-7.7,30.4-31.7$ and $0-0.2 \mathrm{mg} / \mathrm{L}$, respectively. Water temperature ranged from $24^{\circ} \mathrm{C}$ to $28^{\circ} \mathrm{C}$. The same source and quality of water were maintained during the adaption period and trial period.

\section{Experimental design and diets}

After adaptation to experimental conditions, two hundred and forty fish with the initial average body weight of $31.30 \pm 0.05 \mathrm{~g} /$ fish were randomly divided into four groups with three replicates per group and twenty fish per replicate. The four groups were fed basal diet (control group), basal diet + Cd $300 \mathrm{mg} / \mathrm{kg}$; basal diet + Cd $300 \mathrm{mg} / \mathrm{kg}+\mathrm{GSPs} 400 \mathrm{mg} / \mathrm{kg}$, and basal diet + Cd $300 \mathrm{mg} / \mathrm{kg}+$ GSPs $800 \mathrm{mg} / \mathrm{kg}$, respectively. The trial lasted for 42 days.

Ingredients and proximate analyses of the basal diet for pearl gentian groupers are presented in Table 1. The different levels of GSPs (extracted from grape seed, content $>98 \%$, purchased from Nanjing Zelang Medical Technology Co., Ltd., Nanjing, China) were 
supplemented in the basal diet with $300 \mathrm{mg} \mathrm{Cd} / \mathrm{kg}$. All diets were mixed well and pelleted with a $2.5-\mathrm{mm}$ diameter module using a laboratory pellet machine without heating. After processing, the diets were packed into small bags and stored at $-20{ }^{\circ} \mathrm{C}$ until they were fed to the fish.

Table 1. Composition and nutrient levels of the basal diet (air-dry basis)

\begin{tabular}{llll}
\hline Ingredients & $\%$ & Nutrient levels & $\%$ \\
\hline Fish meal & 42.0 & Dry matter & 92.39 \\
Soybean meal & 27.0 & Crude protein & 46.92 \\
Wheat flour & 19.9 & Lipid & 9.88 \\
Shrimp meal & 3.0 & Ash & 10.22 \\
Fish oil & 2.0 & & \\
Soybean oil & 2.0 & & \\
Lecithin & 2.0 & & \\
Choline chloride & 0.3 & & \\
Ca(H $\left.\mathrm{H}_{2} \mathrm{PO}_{4}\right)_{2}$ & 1.0 & & \\
Mineral Premix & 0.5 & & \\
Vitam in premix & 0.3 & & \\
Total & 100.0 & & \\
\hline
\end{tabular}

\section{Sample collection and analysis}

At the end of the trial, all fish in one aquarium was weighted after $24 \mathrm{~h}$ of fasting. Ten fish from each group were randomly anesthetized with $50 \mathrm{~mL} / \mathrm{L}$ eugenol oil suspension. The fish intestines were dissected on ice and kept frozen at $-80{ }^{\circ} \mathrm{C}$ for further measurements. According to the methods of Zhai et al. (2016), the activities of amylase, lipase and protease in the intestine were analyzed by UV-Vis spectrophotometer (UV-1200, Shanghai Mipoda Instrument Co., Ltd., China). The malondialdehyde (MDA) level, total antioxidant capacity (TAOC) activity, superoxide dismutase (SOD) activity, catalase (CAT) activity, and glutathione peroxidase (GSH-Px) activity were tested by Multifunctional Microplate Reader (TECAN Infinite 200 PRO, Tecan Austria $\mathrm{GmbH}$, Austria) with commercial kits according to the descriptions of Zhai et al. (2016; 2018). The level of MDA was expressed as nmol/mg protein. The values of T-AOC, GSH-Px, SOD and CAT activities were expressed as units per mg protein. The Protein concentrations of the intestinal suspension were determined by the Detergent Compatible Bradford Protein Assay Kit. The analytical kits for digestive enzymes and antioxidant parameters were provided by Nanjing Jiancheng Bioengineering Institute (China). Another three fish from each replicate were selected at random and stored at $-20^{\circ} \mathrm{C}$ for subsequent analysis of whole fish body composition. The analyses of proximate composition on trial diets and whole fish were performed according to the methods of Zhai et al. (2014). The contents of moisture, crude protein, lipid, ash, calcium ( $\mathrm{Ca})$, and phosphorus $(\mathrm{P})$ of whole fish were measured by standard methods (AOAC, 1995). The cadmium content of whole fish was analyzed by using Inductively Coupled Plasma Optical Emission Spectroscopy (Prodigy 7, LEEMAELABS, USA).

\section{Data calculation}

At the beginning and the end of the trial, fish weight was measured in each aquarium after $24 \mathrm{~h}$ of feed deprivation. The initial fish weight (IFW), final fish weight (FFW), weight gain rate (WGR), feed conversion ratio (FCR), feeding rate (FR) and survival rate (SR) were calculated as follows:

IFW $(g /$ fish $)=$ initial fish weight of fish per aquarium $(g) /$ initial number of fish.

FFW $(\mathrm{g} /$ fish $)=$ final fish weight of fish per aquarium $(\mathrm{g}) /$ final number of fish.

WGR $(\%)=100 \times[$ final fish weight $(\mathrm{g} /$ fish $)$ - initial fish weight $(\mathrm{g} / \mathrm{fish})] /$ initial fish weight (g/fish).

$\mathrm{FCR}=$ feed intake ( $\mathrm{g}$ /aquarium)/weight gain ( $\mathrm{g}$ /aquarium) .

FR $(\%)=100 \times$ feed consumption ( $\mathrm{g} /$ aquarium)/average fish weight ( $\mathrm{g} /$ aquarium).

$\mathrm{SR}(\%)=100 \times$ (final number of fish per aquarium /initial number of fish per aquarium). 


\section{Statistical analysis}

The results are presented as means \pm SD of four replicates. Statistical analysis was performed with SPSS 22.0 statistical software (SPSS, Chicago, IL, USA). Data from each treatment group were subjected to one-way analysis of variance (ANOVA). When overall differences were significant $(P<0.05)$, Duncan's multiple range test was used to compare the mean values among four treatment groups. Data expressed as percentages were subjected to arcsine square root transformation before statistical analysis.

\section{Results}

\section{Parameters of growth performance}

The effects of dietary GSPs supplementation on the growth performance of pearl gentian grouper under dietary Cd stress are shown in Table 2. Compared with the control group, FFW, WGR, and FR of Cd group decreased significantly $(P<0.05)$, FCR and SR were similar between those two groups $(P>0.05)$. Compared with the Cd group, FFW, WGR, and FCR of Cd+GSPs group II improved significantly $(P<0.05)$, and FR increased significantly in Cd+GSPs groups $(P<0.05)$. SR values were similar among all the groups $(P>0.05)$.

Table 2. Effects of dietary GSPs supplementation on growth performance of pearl gentian grouper exposed to dietary Cd stress

\begin{tabular}{lllll}
\hline Items & Control group & Cd group & Cd+GSPs group I & Cd+GSPs group II \\
\hline IFW (g/fish) & $31.24 \pm 0.89$ & $31.28 \pm 0.11$ & $31.31 \pm 0.05$ & $31.34 \pm 0.05$ \\
FFW (g/fish) & $73.80 \pm 0.20^{\mathrm{c}}$ & $64.45 \pm 1.05^{\mathrm{a}}$ & $64.32 \pm 0.98^{\mathrm{a}}$ & $66.63 \pm 0.58^{\mathrm{b}}$ \\
WGR (\%) & $135.69 \pm 0.64^{\mathrm{c}}$ & $105.91 \pm 3.36^{\mathrm{a}}$ & $105.51 \pm 3.12^{\mathrm{a}}$ & $112.88 \pm 1.86^{\mathrm{b}}$ \\
FCR & $1.00 \pm 0.04^{\mathrm{a}}$ & $1.00 \pm 0.03^{\mathrm{a}}$ & $1.04 \pm 0.02^{\mathrm{ab}}$ & $1.08 \pm 0.01^{\mathrm{b}}$ \\
FR (\%) & $1.92 \pm 0.08^{\mathrm{c}}$ & $1.65 \pm 0.00^{\mathrm{a}}$ & $1.78 \pm 0.02^{\mathrm{b}}$ & $1.79 \pm 0.02^{\mathrm{b}}$ \\
SR (\%) & $100.00 \pm 0.00$ & $98.33 \pm 2.89$ & $100.00 \pm 0.00$ & $98.33 \pm 2.89$
\end{tabular}

IFW=initial fish weight; $F F W=$ final fish weight; $W G R=$ weight gain rate; $F C R=$ feed conversion ratio; $F R=$ feeding rate; $\mathrm{SR}=$ survival rate.

${ }^{a b c}$ Values within the same row without the same superscript were significantly different at $\mathrm{P}<0.05$ level.

\section{Parameters of body composition}

The effects of dietary GSPs supplementation on the body composition of pearl gentian grouper under dietary Cd stress are shown in Table $\mathbf{3}$.

Table 3. Effects of dietary GSPs supplementation on body composition of pearl gentian grouper exposed to dietary Cd stress

\begin{tabular}{lcccc}
\hline Items & Control group & Cd group & Cd+GSPs group I & Cd+GSPs group II \\
\hline Moisture (\%) & $71.35 \pm 0.08$ & $71.55 \pm 0.25$ & $71.18 \pm 0.37$ & $71.67 \pm 0.13$ \\
Crude protein (\%) & $17.35 \pm 0.09$ & $17.23 \pm 0.31$ & $17.26 \pm 0.11$ & $17.24 \pm 0.16$ \\
Lipid (\%) & $6.04 \pm 0.31$ & $5.83 \pm 0.14$ & $5.93 \pm 0.13$ & $5.93 \pm 0.08$ \\
ash (\%) & $4.32 \pm 0.14^{\mathrm{a}}$ & $4.54 \pm 0.09^{\mathrm{b}}$ & $4.51 \pm 0.14^{\mathrm{b}}$ & $4.45 \pm 0.11^{\mathrm{ab}}$ \\
$\mathrm{Ca}(\mathrm{mg} / \mathrm{g})$ & $11.09 \pm 1.33^{\mathrm{b}}$ & $6.01 \pm 0.96^{\mathrm{a}}$ & $13.19 \pm 0.64^{\mathrm{c}}$ & $24.74 \pm 1.02^{\mathrm{d}}$ \\
$\mathrm{P}(\mathrm{mg} / \mathrm{g})$ & $8.08 \pm 0.56^{\mathrm{b}}$ & $4.82 \pm 0.65^{\mathrm{a}}$ & $10.82 \pm 0.71^{\mathrm{c}}$ & $18.79 \pm 0.72^{\mathrm{d}}$ \\
Cd (ug/g) & $1.11 \pm 0.08^{\mathrm{a}}$ & $4.35 \pm 0.33^{\mathrm{d}}$ & $3.73 \pm 0.37^{\mathrm{c}}$ & $2.90 \pm 0.14^{\mathrm{b}}$ \\
\hline
\end{tabular}

${ }^{a b c d}$ Values within the same row without the same superscript were significantly different at $\mathrm{P}<0.05$ level.

There were no significant differences in contents of moisture, crude protein, and lipid among the four treatment groups $(\mathrm{P}>0.05)$. The ash content of the $\mathrm{Cd}$ group and the $\mathrm{Cd}+\mathrm{GSPs}$ group I were significantly higher than that of the control group $(\mathrm{P}<0.05)$. The levels of $\mathrm{Ca}$ and $\mathrm{P}$ decreased significantly in $\mathrm{Cd}$ group compared with the control group $(\mathrm{P}<0.05)$. They increased significantly in $C d+$ GSPs groups $(P<0.05)$, and there was a significant 
difference between the Cd+GSPs group I and the Cd+GSPs group II. The Cd level in Cd group was significantly higher in the control group $(P<0.05)$. Cd levels in $C d+G S P s$ groups decreased significantly in comparison with $C d$ group $(P<0.05)$, and they were still significantly higher than that in the control group $(P<0.05)$. A significant difference in $C d$ level was found between $\mathrm{Cd}+\mathrm{GSPs}$ group I and Cd+GSPs group II $(\mathrm{P}<0.05)$.

\section{Activities of digestive enzymes in intestine}

The effects of dietary GSPs supplementation on digestive enzyme activities in the intestine of pearl gentian grouper under dietary Cd stress are shown in Table 4. Compared with control group, lipase and protease activities in the intestine of the $\mathrm{Cd}$ group decreased significantly $(P<0.05)$. There was no significant difference in lipase activity among treatment groups exposed to dietary $C d$ stress $(P>0.05)$. No significant difference of the protease activity was found between of the Cd+GSPs group I and the Cd+GSPs group II ( $P>0.05)$, while protease activity in the Cd+GSPs group II was significantly higher than that of the Cd group $(P<0.05)$. There was no significant difference of amylase activity among the four treatment groups $(P>0.05)$.

Table 4. Effects of dietary GSPs supplementation on digestive enzymes activities in the intestine of pearl gentian grouper exposed to Cd stress

\begin{tabular}{lcccc}
\hline Items & Control group & Cd group & Cd+GSPs group I & Cd+GSPs group II \\
\hline Amylase (U/mg prot) & $0.40 \pm 0.02$ & $0.41 \pm 0.02$ & $0.40 \pm 0.02$ & $0.41 \pm 0.02$ \\
Lipase (U/mg prot) & $49.45 \pm 2.41^{\mathrm{b}}$ & $44.22 \pm 0.67^{\mathrm{a}}$ & $44.98 \pm 1.74^{\mathrm{a}}$ & $46.65 \pm 3.20^{\mathrm{ab}}$ \\
Protease (U/mg prot) & $88.42 \pm 2.00^{\mathrm{c}}$ & $75.88 \pm 3.65^{\mathrm{a}}$ & $80.09 \pm 2.05^{\mathrm{ab}}$ & $82.69 \pm 1.20^{\mathrm{b}}$ \\
\hline
\end{tabular}

${ }^{a b c}$ Values within the same row without the same superscript were significantly different at $\mathrm{P}<0.05$ level.

\section{Antioxidant parameters in intestine}

The effects of GSPs on antioxidant parameters in intestine of pearl gentian grouper under $\mathrm{Cd}$ stress are presented in Table 5. MDA level in $\mathrm{Cd}$ group increased significantly in comparison with that of the control group $(P<0.05)$, and it decreased significantly by dietary GSPs supplementation $(P<0.05)$. Levels of MDA in the two $C d+G S P s$ groups were higher significantly than that of control group $(P<0.05)$. Activities of T-AOC, SOD, CAT, and GSH-Px in $\mathrm{Cd}$ group decreased significantly in comparison with the control group $(P<0.05)$. They were increased by dietary GSPS supplementation to certain extent. Only T-AOC activity of the Cd+GSPs groups and SOD activity of the Cd+GSPs group II were higher in comparison with those of the Cd group $(P<0.05)$.

Table 5. Effects of dietary GSPs supplementation on antioxidant parameters in the intestine of pearl gentian grouper exposed to Cd stress

\begin{tabular}{lcccc}
\hline Items & Control group & Cd group & Cd+GSPs group I & Cd+GSPs group II \\
\hline MDA (nmol/ mg prot) & $4.14 \pm 0.14^{\mathrm{a}}$ & $7.85 \pm 0.14^{\mathrm{c}}$ & $5.70 \pm 0.53^{\mathrm{b}}$ & $5.98 \pm 0.13^{\mathrm{b}}$ \\
T-AOC (U/mg prot) & $3.31 \pm 0.06^{\mathrm{d}}$ & $2.18 \pm 0.05^{\mathrm{a}}$ & $2.44 \pm 0.03^{\mathrm{b}}$ & $2.78 \pm 0.03^{\mathrm{c}}$ \\
SOD (U/mg prot) & $13.00 \pm 0.24^{\mathrm{c}}$ & $10.34 \pm 0.25^{\mathrm{a}}$ & $10.31 \pm 0.65^{\mathrm{a}}$ & $11.08 \pm 0.85^{\mathrm{b}}$ \\
CAT (U/mg prot) & $8.90 \pm 0.66^{\mathrm{b}}$ & $5.54 \pm 0.81^{\mathrm{a}}$ & $5.62 \pm 0.6^{\mathrm{a}}$ & $6.47 \pm 0.12^{\mathrm{a}}$ \\
GSH-Px (U/mg prot) & $1.42 \pm 0.10^{\mathrm{b}}$ & $1.22 \pm 0.02^{\mathrm{a}}$ & $1.29 \pm 0.08^{\mathrm{a}}$ & $1.31 \pm 0.04^{\mathrm{a}}$ \\
\hline
\end{tabular}

$\mathrm{MDA}=$ malondialdehyde; $\mathrm{T}-\mathrm{AOC}=$ total antioxidant capacity $; \mathrm{SOD}=$ superoxide dismutase $; \mathrm{CAT}=$ catalase; $\mathrm{GSH}-$ $\mathrm{PX}=$ glutathione peroxidase.

abcd Values within the same row without the same superscript were significantly different at $P<0.05$ level. 


\section{Discussion}

In the present study, the growth performance of pearl gentian grouper was severely decreased by dietary $300 \mathrm{mg} / \mathrm{kg}$ dietary Cd exposure. Similar growth inhabitations by certain level of dietary $\mathrm{Cd}$ in inorganic form were confirmed in many other fish species, such as cobia (Rachycentron canadum L.) at $10.90 \mathrm{mg} / \mathrm{kg}$ (Liu et al., 2015), Nile tilapia(Oreochromis niloticus) at $25 \mathrm{mg} / \mathrm{kg}$ (Ayyat et al., 2017), rockfish (Sebasres schlegeli) at $25 \mathrm{mg} / \mathrm{kg}$ (Kim et al., 2004; Kang et al., 2005), yellow catfish (Pelteobagrus fulvidraco) at $48.57 \mathrm{mg} / \mathrm{kg}$ (Tan et al., 2010), genetic improvement of farmed tilapia (GIFT) at $100 \mathrm{mg} / \mathrm{kg}$ (Lu, 2014), crucian carp (Carassius auratus) at $120 \mathrm{mg} / \mathrm{kg}(\mathrm{Kim}, 2009)$, and Parrotfish (Oplegnathus fasciatus) at $162 \mathrm{mg} / \mathrm{kg}$ (Okorie et al., 2014), and goldfifish (subspecies: Prussian carp Carassius auratus gibelio B.) at $10000 \mathrm{mg} / \mathrm{kg}$ (wet weight) (Szczerbik et al., 2006). The growth of Japanese seabass (Lateolabrax japonicus) was also suppressed by dietary organic Cd at $12.08 \mathrm{mg} / \mathrm{kg}$ (Mai et al., 2006). While no significant inhabitation effects of dietary inorganic Cd on growth performance were found in juvenile turbot (Scophthalmus maximus L.) at $50 \mathrm{mg} / \mathrm{kg}$ (Cui et al., 2016), and gibel carp (Carassius gibelio) at $120 \mathrm{mg} / \mathrm{kg}$ (Li et al., 2020), Atlantic salmon (salmo salar) at $250 \mathrm{mg} / \mathrm{kg}$ (Lundebye et al., 1999). Similarly, the growth of cobia (Rachycentron canadum L.) was not affected by dietary organic Cd at $10.90 \mathrm{mg} / \mathrm{kg}$ (Liu et al., 2015). The above results showed that growth inhibition effects caused by dietary Cd were different for different fish species and levels and form of $\mathrm{Cd}$. For the most of previous studies, the inorganic $\mathrm{Cd}$ was the main form in diet, the toxicity of other form $\mathrm{Cd}$ should be studied in further researches. In the present trial, GSPs supplementation improved the growth performance of pearl gentian grouper in comparison to the Cd group, and could not recover to those of the control group without dietary Cd stress. The fish in our trial might be under severe stress induced by $300 \mathrm{mg} / \mathrm{kg}$ dietary Cd, and $800 \mathrm{mg} / \mathrm{kg}$ GSPs might be too low to relieve this severe stress thoroughly. In a previous study, GIFT tilapia fed $400 \mathrm{mg} / \mathrm{kg}$ dietary GSPs under $100 \mathrm{mg} / \mathrm{kg}$ Cd stress had better growth performance than the control group. Similarly, $300 \mathrm{mg} / \mathrm{kg}$ GSPs supplementation could effectively counteract the adverse effects on the growth of juvenile American eel exposed to $300 \mathrm{mg} / \mathrm{kg}$ dietary histamine. In addition, GSPs can significantly improve the growth performance of heat-stressed green-lipped abalone, and increase the survival rate (Shiel et al., 2017).

In the present trial, no significant effect of dietary $\mathrm{Cd}$ was found on whole fish body composition except contents of ash, $\mathrm{Ca}$, and $\mathrm{P}$ of pearl gentian grouper. These results indicated that the dietary $\mathrm{Cd}$ exposure could cause abnormal mineral metabolism with decreasing levels of $\mathrm{Ca}$ and $\mathrm{P}$ and increasing levels of ash and $\mathrm{Cd}$. Similar results were also shown in the studies of other fish species exposed to dietary $\mathrm{Cd}$ stress. The parameters of body composition were not affected by dietary Cd in turbot at $50 \mathrm{mg} / \mathrm{kg}$ (Cui et al., 2016), Japanese seabass at $12.08 \mathrm{mg} / \mathrm{kg}$ (Mai et al., 2006), and Nile tilapia fed dietary Cd at 25 $\mathrm{mg} / \mathrm{kg}$ (Ayyat et al., 2017). In comparison, higher levels of moisture and ash and lower levels of crude protein and lipid were found in yellow catfish exposed to $48.75 \mathrm{mg} / \mathrm{kg}$ dietary Cd (Tan et al., 2010) and cobia exposed to $10.90 \mathrm{mg} / \mathrm{kg}$ dietary Cd (Liu et al., 2015). The Cd accumulation in the above studies increased significantly without exception. The above results indicated that response on body composition of different fish species might have different sensitivities under dietary Cd stress. In the present trial, as the level of dietary GSPs supplementation increased, there was a trend of ash content recovered to that of the control group with increased accumulation of $\mathrm{Ca}$ and $\mathrm{P}$ as well as decreased accumulation of $\mathrm{Cd}$. These might contribute to the improvement of detoxification capacity of pearl gentian grouper by GSPs' antioxidant property and heavy metal chelating property (Nazima et al., 2015; Miltonprabu et al., 2016). According to the findings of Nazima et al. (2016), the chelating Cd effect could be due to the presence of functional groups involving both hydroxyl groups of ring-B and the 5-hydroxy group of ring-A of GSPs. The specific mechanism of GSPs regulating mineral metabolism disorders should be explained in future research. It was reported that the intestinal health might be improved by GSPs supplemented in the diets of GIFT tilapia (Lu, 2014) and growth retarded marbled eel (Anguilla marmorata) (Zhai et al., 2016). The recovery of digestive enzymes activities and antioxidant parameters in intestine of was caused by GSPs supplementation in diet of pearl gentian grouper exposed to dietary Cd stress, which 
indicated that there might be an improvement of intestinal health to promote the absorption and accumulation of $\mathrm{Ca}$ and $\mathrm{P}$.

In our study, the decreased activities of lipase and protease in Cd group were in agreement with the studies of GIFT tilapia (Lu et al., 2014) and catfish (Silurus asotus) (Sastry and Gupta, 1979) exposed to dietary Cd stress. There were limited relief effects of GSPs supplementation on digestive enzyme activity of pearl gentian grouper under $300 \mathrm{mg} / \mathrm{kg}$ dietary Cd stress. Only the activity of intestinal protease improved significantly by $800 \mathrm{mg} / \mathrm{kg}$ GSPs supplementation, and was still significantly lower than that of the control group without $\mathrm{Cd}$ stress. These results were slightly different from the study of GIFT tilapia receiving 100 $\mathrm{mg} / \mathrm{kg}$ dietary Cd with $300 \mathrm{mg} / \mathrm{kg}$ GSPs supplementation returned to normal lipase and protease activities (Lu, 2014). This might be due to the high intensity of dietary Cd stress at $300 \mathrm{mg} / \mathrm{kg}$ and limited relief efficacy of GSPs supplementation at $800 \mathrm{mg} / \mathrm{kg}$ in the present trial.

In general, the toxic effects of cadmium might be likely caused by its bounding to metallothionein with less activity. The mechanism of toxicity of cadmium is related to disrupting the cellular redox state by competing with essential metals in protein-binding sites, triggering a release of $\mathrm{Fe}^{2+}$ and $\mathrm{Cu}^{2+}$ ions and increased generation of ROS (Topal et al., 2013). The redox activity of cadmium depletes antioxidants and glutathione, causes oxidative stress, enhances lipid peroxidation, and alters the lipid composition of membranes. Cadmiuminduced reactive oxygen intermediates can lead to decreased DNA synthesis and strand breaks (Okorie et al., 2014; El-Tarras et al., 2016; Zhai et al., 2018). The oxidative stress might be a main approach of dietary $\mathrm{Cd}$ to cause the damage of tissue and organ (Alkhedaide et al., 2016; El-Tarras et al., 2016; Zhai et al., 2018). In the present trial, it was found that activities of intestinal CAT, SOD, GSH-Px and T-AOC level decreased significantly along with the increased MDA level. These results indicated that dietary $\mathrm{Cd}$ at $300 \mathrm{mg} / \mathrm{kg}$ could cause the oxidative stress in the intestine of pearl gentian grouper, which was consistent with the results in the intestine of GIFT tilapia exposed to dietary Cd stress (Lu, 2014). Antioxidant defenses in fish were also negatively affected by dietary cadmium exposure in the liver of yellow catfish (Tan et al., 2010) and cobia (Liu et al., 2015), liver and kidney of brown trout (Salmo trutta fario, L) (Topal et al., 2013). Considering the antioxidant parameters in the intestine of pearl gentian grouper exposed to dietary $\mathrm{Cd}$ in the present trial, only decreased MDA level and increased activities T-AOC and SOD were induced by GSPs supplementation, however, the activities of CAT and GSH-Px were not significantly affected. Besides, GSPS supplementation could not return the antioxidant parameters to normal levels. While in the study of GIFT tilapia exposed to Cd stress at $100 \mathrm{mg} / \mathrm{kg}$, MDA level and activities of T-AOC, SOD, CAT, and GSH-Px were normalized by GSPs supplementation at $300 \mathrm{mg} / \mathrm{kg}(\mathrm{Lu}, 2014)$. The results of antioxidant parameters in the intestine of pearl gentian grouper also confirmed that the stress induced by $300 \mathrm{mg} / \mathrm{kg}$ dietary $\mathrm{Cd}$ might be severe to recover to a normal status with GSPs supplementation at $800 \mathrm{mg} / \mathrm{kg}$. Further research should be conducted to achieve the optimal supplementation level of GSPs in diet of pearl gentian grouper exposed to dietary Cd stress at $300 \mathrm{mg} / \mathrm{kg}$.

In conclusion, $800 \mathrm{mg} / \mathrm{kg}$ GSPs supplementation might have a certain ability to reverse the decline of growth performance, levels of $\mathrm{Ca}$ and $\mathrm{P}$, digestive enzymes activities and antioxidant potential of the intestine of pearl gentian grouper exposed to $300 \mathrm{mg} / \mathrm{kg}$ dietary $\mathrm{Cd}$. The negative effects were not alleviated to a normal level due to the high-stress intensity under this trial condition. The alleviation effects of GSPs might be due to their properties of free radical scavenging, metal chelating, and antioxidant potentials.

\section{Acknowledgements}

This study was supported by Natural Science Foundation of Fujian Province (No. 2016J01166) and Engineering Research Center of the Modern Technology for Eel Industry, Ministry of Education, P. R. China (RE202010; RE202111). 


\section{References}

Alkhedaide A., Alshehri Z.S., Sabry A., Abdel-Ghaffar T., Soliman M.M. and H. Attia, 2016. Protective effect of grape seed extract against cadmium-induced testicular dysfunction. Mol. Med. Rep., 13(4): 3101-3109. doi:10.3892/mmr.2016.4928

AOAC,1995. Official Methods of Analysis of the AOAC international, $16^{\text {th }}$ ed. Association of Official Analytical Chemists International, Washington, DC, USA.

Ayyat M.S., Mahmoud H.K., El-Hais A.E.M. and K.M. Abd El-Latif, 2017. The role of some feed additives in fish fed on diets contaminated with cadmium. Environ. Sci. Pollut. R., 24(30):23636-23645. doi: 10.1007/s11356-017-9986-1

Chen Q., Zhang R., Li W., Niu Y., Guo H., Liu X., Hou Y. and L. Zhao, 2013. The protective effect of grape seed procyanidin extract against cadmium-induced renal oxidative damage in mice. Environ. Toxicol. Phar., 36(3):759-768. doi:10.1016/ j.etap.2013.07.006

Cui L., Xu W., Wang D., Zuo R., Mai K. and Q. Ai, 2016. Alleviation effect of dietary cerium and its complex with chitosan oligosaccharide on cadmium accumulation in juvenile turbot, Scophthalmus maximus L., under cadmium stress. Aquac. Res., 47(8):2426-2434. doi:10.1111/are.12690

El-Tarras A.E., Attia H.F., Soliman M.M., El Awady M.A. and A.A. Amin, 2016 Neuroprotective effect of grape seed extract against cadmium toxicity in male albino rats. Int. J. Immunopath. Ph., 29(3):398-407. 10.1177/0394632016651447

Evcimen M., Aslan R. and M.S. Gulay, 2020. Protective effects of polydatin and grape seed extract in rats exposed to cadmium. Drug Chem. Toxicol., 43(3): 225-233. doi: $10.1080 / 01480545.2018 .1480629$

Fine A.M., 2000. Oligomeric proanthocyanidin complexes: history, structure, and phytopharmaceutical applications. Altern. Med. Rev., 5(2): 144-151.

Hou F., Xiao M., Li J., Cook D.W., Zeng W., Zhang C. and Y. Mi, 2016. Ameliorative effect of grape seed proanthocyanidin extract on cadmium-induced meiosis inhibition during oogenesis in chicken embryos. Anat. Rec., 299(4):450-460. doi: 10.1002/ar. 23320

Kang J.C., Kim S.G. and S.W. Jang, 2005. Growth and hematological changes of rockfish, Sebastes schlegeli (hilgendorf) exposed to dietary $\mathrm{Cu}$ and Cd. J. World Aquacult. Soc., 36(2):188-195. doi:10.1111/j.1749-7345.2005.tb00384.x

Kim S.G., Kim J.W. and J.C. Kang, 2004. Effect of dietary cadmium on growth and haematological parameters of juvenile rockfish, Sebastes schlegeli (Hilgendorf). Aquac. Res., 35(1):80-86. doi:10.1111/j.1365-2109.2004.00991.x

Kim S., Du H., Dai W., Zhang X. and Z. Xu, 2009. Influence of montmorillonite on cadmium accumulation in carp, Carassius auratus. Appl. Clay Sci., 43(3-4):473-476. doi: 10.1016/j.clay.2008.12.003

Lei Y., Chen Q., Chen J. and D. Liu, 2017. Potential ameliorative effects of grape seedderived polyphenols against cadmium induced prostatic deficits. Biomed. Pharmacother., 91:707-713. doi: 10.1016/j.biopha.2017.05.006

Li H., Xu W., Wu L., Dong B., Jin J., Han D., Zhu X., Yang Y., Liu H. and S. Xie, 2020. Distinct dietary cadmium toxic effects and defense strategies in two strains of gibel carp (Carassius gibelio) revealed by a comprehensive perspective. Chemosphere, 261:127597. doi: $10.1016 /$ j.chemosphere.2020.127597

Liu K., Chi S., Liu H., Dong X., Yang Q., Zhang S. and B. Tan, 2015. Toxic effects of two sources of dietborne cadmium on the juvenile cobia, Rachycentron canadum L. and tissuespecific accumulation of related minerals. Aquat. Toxicol., 165: 120-128. doi: 10.1016/j.aquatox.2015.05.013

Liu Y., Wang J., Li B., Qiao H., Liu X., Hao T. and X. Wang, 2018. Dietary manganese requirement of juvenile hybrid grouper, Epinephelus lanceolatus ô $\times$ Epinephelus fuscoguttatus . Aquacult. Nutr., 24 (1): 215-223. doi: 10.1111/anu.12549

Lu J., 2014. The effects of dietary oligomeric proanthocyanidins supplementation on the growth and oxidative stress of juvenile GIFT tilapia (Oreochromis niloticus). Master Thesis, Jimei University, Xiamen, China. 
Lundebye A.K., Berntssen M.H.G., Bonga S.E.W. and A. Maage, 1999. Biochemical and physiological responses in Atlantic salmon (salmo salar) following dietary exposure to copper and cadmium. Mar. Pollut. Bull., 39:137e144. doi:10.1016/S0025-326X(98) 00208-2.

Mai K., Li H., Ai Q., Duan Q., Xu W., Zhang C., Zhang L., Tan B. and Z. Liufu, 2006. Effects of dietary squid viscera meal on growth and cadmium accumulation in tissues of Japanese seabass, Lateolabrax japonicus (Cuvier 1828). Aquac. Res., 37(11): 1063-1069. doi:10.1111/j.1365-2109.2006.01529.x

Miltonprabu S., Bashir N. and Vaihundam. M, 2016. Hepatoprotective effect of grape seed proanthocyanidins on Cadmium-induced hepatic injury in rats: Possible involvement of mitochondrial dysfunction, inflammation and apoptosis. Toxicol. Rep., 3:63-77. doi:10.1016/ j.toxrep.2015.11.010

Morsi A.A., Shawky L.M. and E.A. El Bana, 2020. The potential gonadoprotective effects of grape seed extract against the histopathological alterations elicited in an animal model of cadmium-induced testicular toxicity. Folia Morphol., 79(4):767-776. doi: 10.5603/FM.a2020. 0003

Nazima B., Manoharan V. and S. Miltonprabu, 2015. Grape seed proanthocyanidins ameliorates cadmium-induced renal injury and oxidative stress in experimental rats through the up-regulation of nuclear related factor 2 and antioxidant responsive elements. Biochem. Cell. Biol., 93(3):210-226. doi:10.1139/bcb-2014-0114

Nazima B., Manoharan V. and S. Miltonprabu, 2016. Grape seed proanthocyanidins protects against cadmium induced oxidative pancreatitis in rats by attenuating oxidative stress, inflammation and apoptosis via Nrf-2/HO-1 signaling. J. Nutr. Biochem., 32:128-141. doi: $10.1016 / j$.jnutbio.2016.03.001

Okorie O.E., Bae J.Y., Lee J.H., Lee S., Park G.H., Mohseni M. and S. C. Bai, 2014. Effects of different dietary cadmium levels on growth and tissue cadmium content in juvenile parrotfish, Oplegnathus fasciatus. Asian Australas. J. Anim. Sci., 27(1):62-68. doi:10.5713/ ajas.2011.11222

Sastry K.V. and P.K. Gupta, 1979. The effect of cadmium on the digestive system of the teleost fish, Heteropneustes fossilis. Environ. Res., 19(2): 221-230. doi: 10.1016/ 00139351(79)90050-1

Shiel B.P., Hall N.E., Cooke I.R., Robinson N.A., Stone D.A.J. and J.M. Strugnell, 2017. The effect of commercial, natural and grape seed extract supplemented diets on gene expression signatures and survival of greenlip abalone (Haliotis laevigata) during heat stress. Aquaculture, 479: 798-807. doi:10.1016/j.aquaculture.2017.07.025

Szczerbik P., Mikolajczyk T., Sokolowska-Mikolajczyk A., Socha M., Chyb J. and P. Epler, 2006. Influence of long-term exposure to dietary cadmium on growth, maturation and reproduction of goldfish (subspecies: Prussian carp Carassius auratus gibelio B.). Aquat. Toxicol., 77(2):126-135. doi:10.1016/j.aquatox.2005.11.005

Tan X., Luo Z., Zhang G., Liu X. and M. Jiang, 2010. Effect of dietary cadmium level on the growth, body composition and several hepatic enzymatic activities of juvenile yellow catfish, Pelteobagrus fulvidraco. Aquac. Res., 41(7): 1022-1029. doi: 10.1111/j.13652109.2009.02386.x

Topal A., Alak G., Atamanalp M., Oruc E., Ceyhun S.B., Ucar A., Arslan H., Celebi F. and Y.S. Saglam, 2013. Effects of Humic Acid on Liver and Kidney Toxicity Induced by Cadmium in Brown Trout (Salmo trutta fario, L). Turk. J. Fish. Aquat. Sci., 13(4):621-627. doi: 10.4194/1303-2712-v13_4_07

Zhai S., Lu J., Zhao P. and $\overline{\mathbf{X}}$. Chen, 2014. Effects of dietary grape seed proanthocyanidins on growth performance, some serum biochemical parameters and body composition of tilapia (Oreochromis niloticus) fingerlings. Ital. J. Anim. Sci., 13(3). doi:10.4081/ijas.2014.3357

Zhai S., Lu J., Zhao P. and X. Chen, 2018. Effect of grape seed proanthocyanidins on alleviating dietary cadmium (Cd) induced growth retardation and oxidative stress in hepatopancreas of juvenile tilapia (Oreochromis niloticus). Isr. J. Aquacult-Bamidgeh, 70: 1513. doi.org/10.46989/001c.20925 
Zhai S., Shi Q. and X. Chen, 2016. Effects of dietary surfactin supplementation on growth, digestive enzymes activities and antioxidant potential in intestine of growth retarded marbled eel (Anguilla marmorata) at elver stage. Isr. J. Aquacult-Bamidgeh, 68:1282. doi.org/10.46989/001c.20813

Zhai S., Wang Y., He Y. and X. Chen, 2020. Oligomeric proanthocyanidins counteracts the negative effects of high level of dietary histamine on American eel (Anguilla rostrata). Front. Mar. Sci., 7: 549145. doi:10.3389/fmars.2020.549145 